\title{
Effect of polyaspartic acid on hydroxyapatite deposition in silk fibroin blend films
}

\author{
X. L. Ma, R. Li, L. Ru, G. W. Xu, Y. P. Huang* \\ School of Chemistry and chemical engineering, Key Laboratory of Environment-friendly Polymer Materials of Anhui \\ Provinc, Anhui University; 230039 Hefei, Anhui Province, China
}

\begin{abstract}
Polyaspartic acid/silk fibroin/hydroxyapatite (PASP/SF-HA) composites have been synthesized by biomimetic processing. SF solution was mixed with different contents of PASP to prepare the PASP/SF blend membranes. After ethanol treatment and premineralization process, the blend membranes were immersed into 1.5 simulated body fluid (1.5 SBF) for $24 \mathrm{~h}$ to induce apatite deposition at $37 \pm 0.5^{\circ} \mathrm{C}$. Fourier transform infrared spectroscopy (FTIR) and X-ray diffraction (XRD) results revealed that a conformation transition of SF occurred after the addition of PASP and ethanol treatment. The FTIR and XRD results also confirmed that the main component of apatite deposition was HA. Scanning electron microscopy (SEM) showed that the content of HA increased with increasing PASP concentration .Inductively Coupled Plasma-Atomic Emission Spectrometry (ICP) results revealed that the Ca/P molar ratio could reach 1.45, which was close to the $\mathrm{Ca} / \mathrm{P}$ ratio of apatite. It was appropriate to conclude that the increasing content of PASP had a distinct effect on HA deposition in the blend films.
\end{abstract}

Keywords: biopolymers, biocomposites, hydroxyapatite, silk fibroin, conformation transition

\section{Introduction}

Hydroxyapatite (HA) with the chemical formula of $\mathrm{Ca}_{10}\left(\mathrm{PO}_{4}\right)_{6}(\mathrm{OH})_{2}$, is the major mineral part of natural bones and teeth. HA is the most commonly used apatite-based biomaterial due to its excellent biocompatibility, osteoconductivity and bioactivity [1, 2]. In the past decades, many efforts have been focused on the biomimetic growth of nano-HA through the combination of biodegradable polymers or proteins for bone tissue engineering [3-6]. Among these polymers, collagen is the best known tissue-derived natural polymer and has been used as tissue-culture scaffolds. However, the practical problems with collagen are its cost, and a limited range of physical properties unless extensively crosslinked, which alters biological response [7, 8]. Silk fibroin (SF), used as an appealing alternative polymer, possesses impressive mechanical proper- ties and appreciable bioactivity that make it attractive for artificial bones [9, 10]. Kong et al. [11] employed SF to regulate the mineralization of HA . The effects of SF content on the microstructure and physico-chemical properties of the composite had also been studied [12]. In order to expand its application in biomaterials, the water-insoluble SF films were also prepared by inducing the structure transition from unstable silk I to silk II. The transition was commonly studied through treatment of aqueous ethanol solution $[13,14]$. At the same time, biodegradable polymers such as chitosan [15], cellulose [16] and sodium alginate [17] have been widely used in the conformation transition of SF. Recently, Kim et al. [18] used aqueous-derived porous SF scaffolds mixing with PASP to deposit apatite, which provided an appropriate osteogenic environment for tissue engineering. However, the

*Corresponding author, e-mail: yphuang2001@ sina.com.cn (c) BME-PT 
effect of PASP on the conformation transition of SF has not yet been studied in detail.

In this work, pure SF and various blend ratios of PASP/SF films were prepared. After a premineralization process, the films were immersed into $1.5 \mathrm{SBF}$ for $24 \mathrm{~h}$ to synthesize PASP/SF-HA composite. FT-IR, SEM and XRD spectroscopy were used to study the conformation transition of SF and the morphology of the obtained composite films. After the addition of PASP and treatment of ethanol, the silk I conformation had been transformed to silk II, which enhanced the deposition of HA. The results reported here may provide some information about a new strategy for the synthesis of other composite materials.

\section{Materials and methods}

\subsection{Materials}

$\mathrm{Na}_{2} \mathrm{CO}_{3}, \mathrm{LiBr}, \mathrm{NaCl}, \mathrm{NaHCO}_{3}, \mathrm{KCl}, \mathrm{K}_{2} \mathrm{HPO}_{4} \cdot 3 \mathrm{H}_{2} \mathrm{O}$, $\mathrm{MgCl}_{2} \cdot 6 \mathrm{H}_{2} \mathrm{O}, \mathrm{HCl}, \mathrm{CaCl}_{2}, \mathrm{Na}_{2} \mathrm{SO}_{4}, \mathrm{NaOH}$, tris(hydroxymethyl) aminomethane (Tris) and ethanol used here were analytical grade and purchased from Huipu Chemical Agents Co. Ltd. (Hangzhou, China). B. mori silkworm cocoons were provided by Anhui Agricultural Research Institute.

\subsection{Preparation of SF films and PASP/SF scaffolds}

B. mori silkworm cocoons were boiled for $30 \mathrm{~min}$ in an aqueous solution of $0.5 \%(\mathrm{w} / \mathrm{v}) \mathrm{Na}_{2} \mathrm{CO}_{3}$ and then rinsed thoroughly with distilled water to extract the glue-like sericin protein. The treatment was repeated two times to get the pure silk fibroin. The degummed silk fibroin was air-dried at ambient temperature and dissolved in $9.5 \mathrm{M} \mathrm{LiBr}$ solution for 4 hours at $50^{\circ} \mathrm{C}$ followed by a dialysis (MWCO 14000) against distilled water for 3 days. The final concentration of aqueous silk fibroin solution was approximately $2.7 \%(\mathrm{w} / \mathrm{v})$. Then the solutions were stored in a refrigerator at $7-8^{\circ} \mathrm{C}$ before being used. Then, aqueous SF solution was cast onto polytetrafluoroethylene plates and dried at room temperature for the preparation of SF films. For the preparation of the blend membranes different amounts of PASP solution were added to SF solution under mild stirring for $2 \mathrm{~min}$. The mixing solutions were poured into the polytetrafluoroethylene plates and air-dried at room temperature. The formed PASP/SF films were then treated with $60 \%$ (v/v) ethanol aqueous solution for $20 \mathrm{~min}$.

\subsection{Premineralization and mineralization}

The alternate soaking process was used to grow apatite on silk fibers. First, SF films and PASP/SF scaffolds were soaked in $50 \mathrm{ml}$ of $0.2 \mathrm{M} \mathrm{CaCl}_{2}$ solution (buffered with $0.05 \mathrm{M}$ Tris. $\mathrm{HCl}, \mathrm{pH} 7.4$ ) for $1 \mathrm{~min}$ and washed two times with distilled water. The PASP/SF scaffolds were then transferred to $50 \mathrm{ml}$ of $0.12 \mathrm{M} \mathrm{K}_{2} \mathrm{HPO}_{4}$ solution, soaked for $1 \mathrm{~min}$ and washed two times with distilled water. The soaking cycles were repeated 3 times. The whole process performed at $37^{\circ} \mathrm{C}$.

The premineralized PASP/SF scaffolds were subsequently immersed into $1.5 \mathrm{SBF}$ (Table 1 ) at $37^{\circ} \mathrm{C}$ for $24 \mathrm{~h}$, followed by rinsing with deionized water and air-drying at room temperature.

Table 1. Composition of 1.5 SBF ( $\mathrm{pH} 7.4$ ) and order of addition of the reagents to water [19]

\begin{tabular}{|c|l|c|}
\hline Order & \multicolumn{1}{|c|}{ Reagent } & Weight [g·l-1] \\
\hline 1 & $\mathrm{NaCl}$ & 12.0540 \\
\hline 2 & $\mathrm{NaHCO}_{3}$ & 0.5280 \\
\hline 3 & $\mathrm{KCl}$ & 0.3375 \\
\hline 4 & $\mathrm{~K}_{2} \mathrm{HPO}_{4} \cdot 3 \mathrm{H}_{2} \mathrm{O}$ & 0.3450 \\
\hline 5 & $\mathrm{MgCl}_{2} \cdot 6 \mathrm{H}_{2} \mathrm{O}$ & 0.4665 \\
\hline 6 & $1 \mathrm{M} \mathrm{HCl}$ & $15.00 \mathrm{ml}$ \\
\hline 7 & $\mathrm{CaCl}_{2}$ & 0.4440 \\
\hline 8 & $\mathrm{Na}_{2} \mathrm{SO}_{4}$ & 0.1080 \\
\hline 9 & $\mathrm{C}_{4} \mathrm{H}_{11} \mathrm{NO}_{3}$ (Tris) & 9.0945 \\
\hline 10 & $1 \mathrm{M} \mathrm{HCl}^{2}$ & $50.00 \mathrm{ml}$ \\
\hline
\end{tabular}

\subsection{Characterization}

The FT-IR spectra of samples were measured with Fourier transform infrared spectroscopy (FTIR) (Nicolet NEXUS-870, USA), the apatite deposited SF films samples were mixed with $\mathrm{KBr}$ in the mass ratio of 1:20-30. Infrared spectra were taken in the range of $4000-400 \mathrm{~cm}^{-1}$ with $4 \mathrm{~cm}^{-1}$ resolution. To investigate the structure and crystallinity, the milled sample powder were analyzed on an X-ray powder diffractometer (XRD) (Philiphs X'PertPros, Dutch) using a diffractometer equipped for $\mathrm{Cu}-\mathrm{K}_{\alpha}$ radiation $(\lambda=0.15418 \mathrm{~nm})$ in the $2 \theta$ range of $10-60^{\circ}$ at $40 \mathrm{kV}$ and $30 \mathrm{~mA}$. The morphology of apatite deposited SF films sputtered with gold was 
examined using scanning electron microscopy (SEM) (S-4800, Hitachi, Japan) with an accelerating voltage of $5 \mathrm{kV}$. The content of $\mathrm{Ca}$ and $\mathrm{P}$ elements in the composites was analyzed by Inductively Coupled Plasma-Atomic Emission Spectrometry (ICP) (IRIS Intrepid II ICP-OES, Thermo ELECTRON CORPORPORATION, USA). The milled composites samples were dissolved with $\mathrm{HNO}_{3}$ and $\mathrm{HClO}_{4}$, then they were filled to constant volume, with distilled water to $25 \mathrm{ml}$.

\section{Results and discussion}

\subsection{FTIR}

The conformational transition of SF and the composite films were studied by FT-IR spectroscopy (Figure 1). Figure 1a shows the characteristic peaks of PASP, including the $\mathrm{C}=\mathrm{O}$ peaks at $1733 \mathrm{~cm}^{-1}$ and the $\mathrm{C}-\mathrm{N}$ stretching vibrational frequencies at $1398 \mathrm{~cm}^{-1}$, the bands at 3358 and $1586 \mathrm{~cm}^{-1}$ corresponding to the stretching vibration and bending vibration of $\mathrm{N}-\mathrm{H}$ bonds, respectively. The bands for pure SF (Figure 1b) at $1658 \mathrm{~cm}^{-1}$ (amide I), $1550 \mathrm{~cm}^{-1}$ (amide II), $1243 \mathrm{~cm}^{-1}$ (amide III) and $670 \mathrm{~cm}^{-1}$ (amide V) were attributed to silk I form. After the addition of PASP, the band at $1658 \mathrm{~cm}^{-1}$ showed an obvious shift, the 1550 and $1243 \mathrm{~cm}^{-1}$ bands shift to lower wave number, the shifts were 7 and $4 \mathrm{~cm}^{-1}$, respectively. Furthermore, the shift

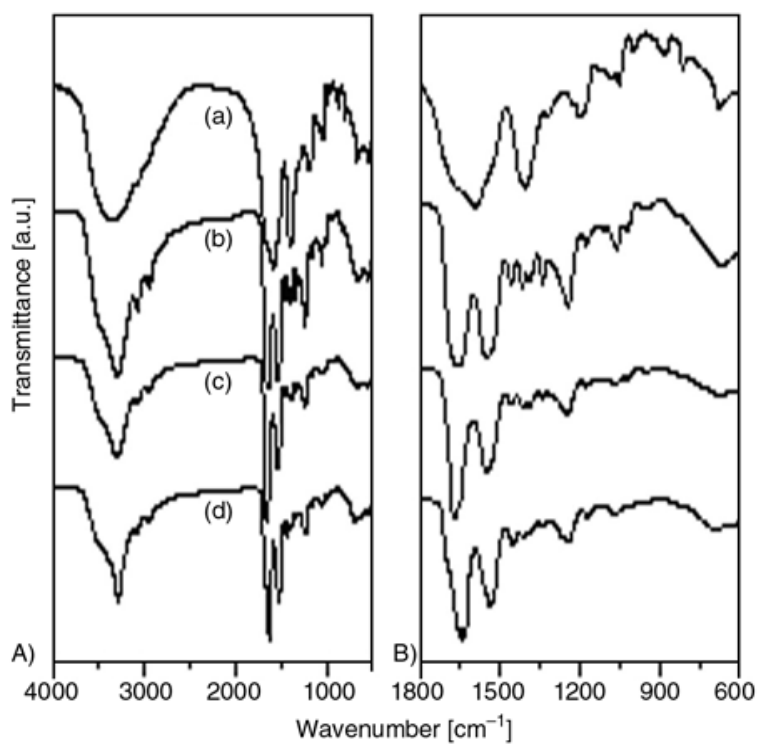

Figure 1. FT-IR spectra of (a) PASP, (b) SF, (c) PASP/SF and (d) PASP/SF treated with $60 \%(\mathrm{v} / \mathrm{v})$ ethanol aqueous solution. The blend ratio of PASP/SF solution was $10 \%$ (w/w). (A) $4000-500 \mathrm{~cm}^{-1}$ range. (B) Detail of the $1800-600 \mathrm{~cm}^{-1}$ region. of amide peaks was more evident after ethanol treatment. In order to clearly reflect conformation transition of the SF in the blend membranes, the spectral ranges of $1800-600 \mathrm{~cm}^{-1}$ were shown in Figure 1B. The amide I and amide II bands for the PASP/SF composite films were shifted from 1658 to 1662 and 1550 to $1542 \mathrm{~cm}^{-1}$, respectively, and a small sharp peak at $1649 \mathrm{~cm}^{-1}$ appeared, indicating that a partial conformation transition from silk I to silk II structure occurred [11]. After treated with ethanol, the amide I bands were shifted to $1634 \mathrm{~cm}^{-1}$ with a shoulder at $1694 \mathrm{~cm}^{-1}$, which could be assigned to $\beta$-turns [20, 21]. Amide II and amide III bands were shifted to 1526 and $1233 \mathrm{~cm}^{-1}$, respectively. The shift of amide bands demonstrated that intermolecular interactions may be formed between the polymer functional groups, such as hydrogen bonding of carbonyl groups of PASP, hydroxyl groups of ethanol, amide groups of $\mathrm{SF}$, which might be related to the conformational transition of SF. From the above results, it was obvious that the addition of PASP changed the structure of SF, and ethanol treatment can further promote this change.

Figure 2 shows the FT-IR spectra of the mineralized scaffolds prepared from various blend ratios of PASP/SF solutions. It could be seen that the spectra of the mineralized scaffolds displayed the absorption bands at 1040, 603 and $564 \mathrm{~cm}^{-1}$ (Figure 2: a, b, c, d), and the intensity of these peaks gradually enhanced with the increasing content of PASP. Compared with the infrared data of pure HA (Fig-

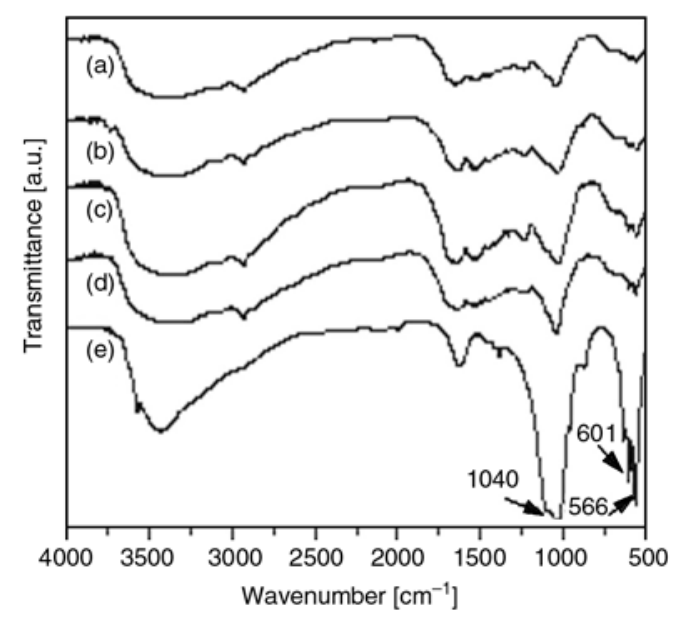

Figure 2. FT-IR spectra of the mineralized scaffolds prepared from various blend ratios of PASP/SF solutions (a: $0 \%$; b: $5 \%$; c: $10 \%$; d: $15 \%$ ) and (e) HA 
ure 2e), the predominant component of the resultant inorganic phase was HA. The results indicated that HA had been successfully deposited on the surface of PASP/SF blend membranes and the carbonyl groups of PASP in the organic template induced the nucleation of HA [22].

\subsection{XRD}

Figure 3 displayed XRD patterns of the prepared scaffolds. For the pure SF film (Figure 3a), only a weak and wide halo pattern appeared, this exceedingly discrete powder diagram belonged to silk I $[23,24]$.According to the studies on silk fibroin molecular conformation [25], the X-ray diffraction patterns had been determined as follows, $11.5^{\circ}(2 \theta)$ for $\alpha$-helix structure, and $20.2^{\circ}(2 \theta)$ for $\beta$-sheet structure. It could be seen from curve (b) that the composite sample showed two peaks around $11.8^{\circ}(2 \theta)$ and $20.2^{\circ}(2 \theta)$. Its molecular conformation exhibited a coexistence of $\alpha$-helix and $\beta$-sheet structure, indicating that PASP partly induced the conformation of SF from silk I to silk II. The characteristic peaks $\left(2 \theta=20.2^{\circ}\right)$ of $\beta$-sheet became more intensive with the treatment of $60 \%(\mathrm{v} / \mathrm{v})$ ethanol aqueous solution (Figure 3b, 3c). It showed that the essential changes of silk fibroin molecular conformation have taken place during the treatment by ethanol.

Figure 3d displays XRD patterns of the PASP/SFHA composite. As shown in Figure 3d, after soak-

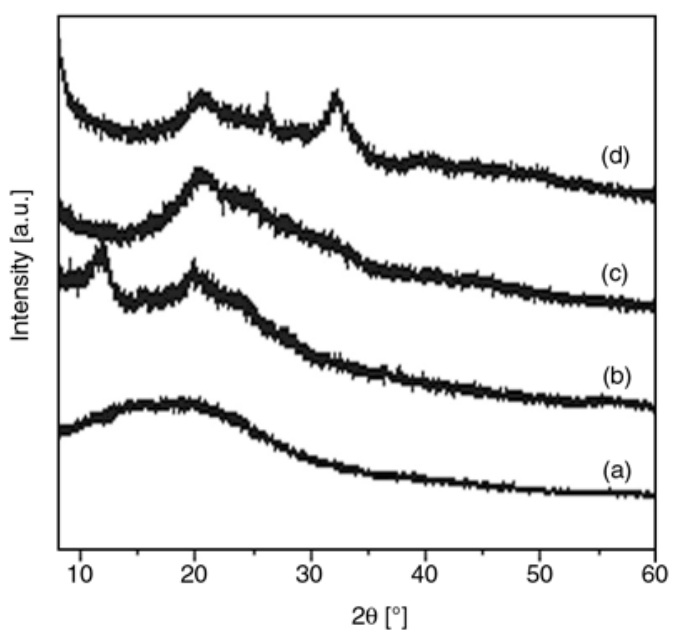

Figure 3. X-ray diffraction of (a) SF, (b) PASP/SF, (c) PASP/SF with the treatment of $60 \%(\mathrm{v} / \mathrm{v})$ ethanol aqueous solution, and (d) the mineralized scaffolds at $37^{\circ} \mathrm{C}$. The blend ratio of PASP/SF solution was $10 \%(w / w)$ ing in $1.5 \mathrm{SBF}$ for $24 \mathrm{~h}$, the clear but weak diffraction peaks were detected at $25.9^{\circ}(2 \theta)$ and $31.9^{\circ}(2 \theta)$ corresponding to the (002) and (211) planes of HA crystal (verified by PDF Card No.09-0432). The result also confirmed that the predominant component of the inorganic phase was HA. The broadened peaks of the (002) and (211) crystal planes showed an imperfect crystallization of HA. This crystallographic structure of HA in the PASP/SF-HA composite was more similar to natural bone mineral. In addition, the organic components in the PASP/SFHA composite also showed a diffraction peak at $20.2^{\circ}(2 \theta)$ in Figure 3d, which assigned to the $\beta$ sheet structure of SF. These results were consistent with the analysis of FTIR.

\subsection{SEM}

The surface morphology of the prepared materials is shown in Figure 4. After addition of PASP, the surface of SF films became rough (Figure 4A: b, c, d). Through the alternate soaking in $\mathrm{CaCl}_{2}$ and $\mathrm{K}_{2} \mathrm{HPO}_{4}$ solutions at $37^{\circ} \mathrm{C}$, some inorganic compounds attached to the film surface and much aggregation occurred with increasing content of PASP. When the blend ratio of PASP reached $15 \%$, a smooth porous surface was formed (Figure 4B: d). Figure 4C shows the SEM images of the scaffolds soaked in $1.5 \mathrm{SBF}$ at $37^{\circ} \mathrm{C}$ for $24 \mathrm{~h}$. The scaffolds formed highly interconnected and porous structure. The general size of the pores got to the maximum with $5 \%(\mathrm{w} / \mathrm{w})$ blend ratio of PASP and higher content PASP resulted in the formation of needle-like apatite assembled into clusters. These results indicated that the composite films could become more homogeneous along with the increasing content of PASP, which could enhance the deposition of apatite. The ICP results of PASP/SF-HA shown in Table 2 also demonstrated the $\mathrm{Ca} / \mathrm{P}$ molar ratio in the scaffolds increased gradually along with addition of PASP. When HA deposited on the pure $\mathrm{SF}$ films, the $\mathrm{Ca} / \mathrm{P}$ molar ratio was only 1.38 . How-

Table 2. ICP results from the PASP/SF-HA composite

\begin{tabular}{|c|c|c|c|}
\hline \multirow{2}{*}{ PASP/SF } & \multicolumn{3}{|c|}{ Element contents in the sample solution* } \\
\cline { 2 - 4 } & Ca [mg/l] & $\mathbf{P}[\mathbf{m g} / \mathbf{l})$ & $\mathbf{C a} / \mathbf{P}$ \\
\hline $100 / 0$ & 43.28 & 24.24 & 1.38 \\
\hline $95 / 5$ & 53.16 & 41.20 & 1.39 \\
\hline $90 / 10$ & 56.74 & 30.50 & 1.44 \\
\hline $85 / 15$ & 56.81 & 30.37 & 1.45 \\
\hline
\end{tabular}

*All samples are of the same quality 


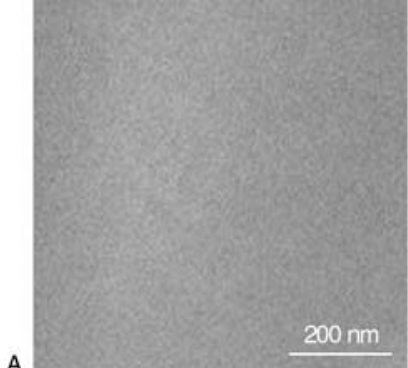

a)

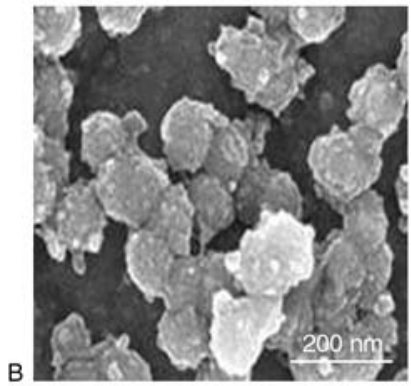

a)

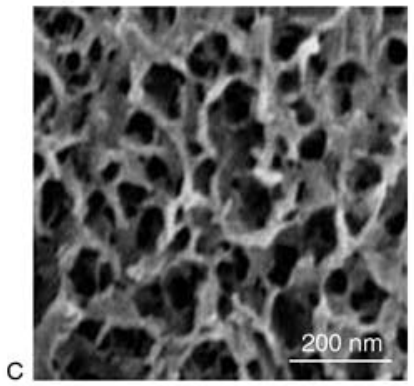

a)

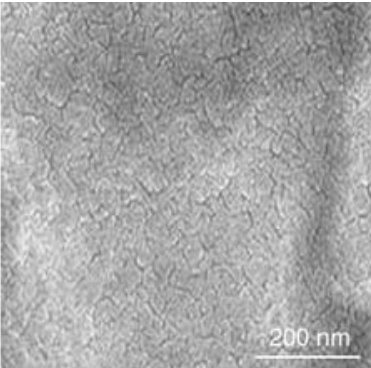

b)

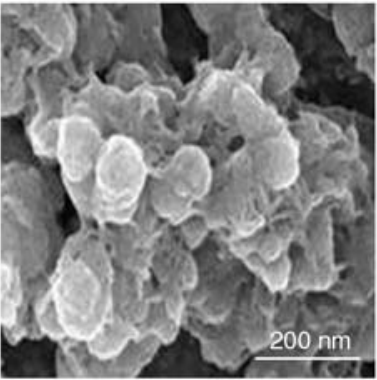

b)

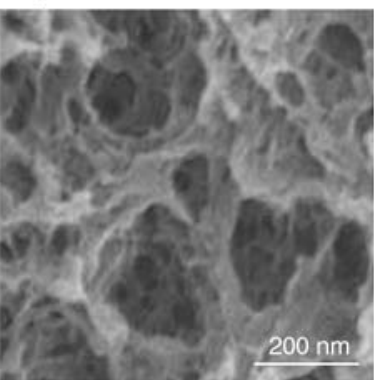

b)

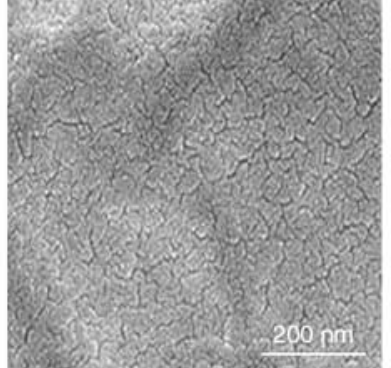

c)

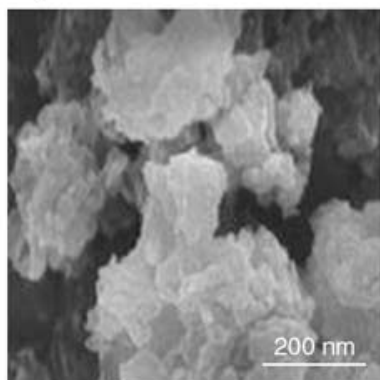

c)

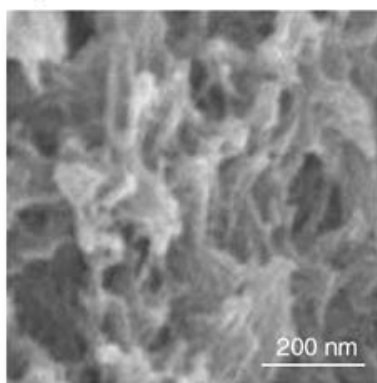

c)

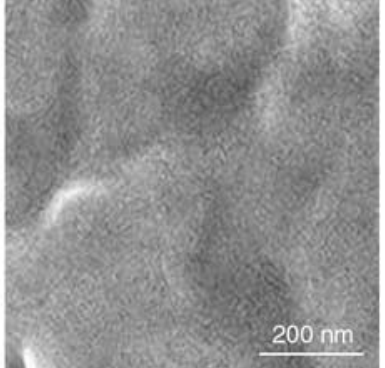

d)

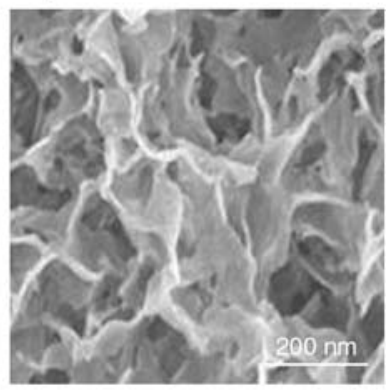

d)

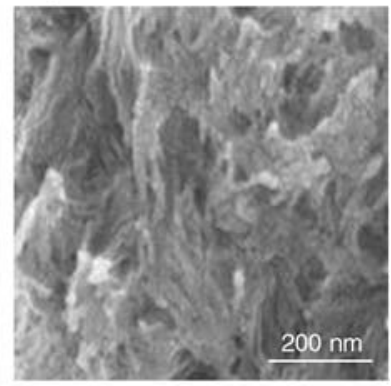

d)

Figure 4. SEM images of the scaffolds (A) prepared from various blend ratios of PASP/SF solutions, (B) after soaking in $\mathrm{CaCl}_{2}$ and $\mathrm{K}_{2} \mathrm{HPO}_{4}$ solutions at $37^{\circ} \mathrm{C}$, and $(\mathrm{C})$ followed by being soaked in $1.5 \mathrm{SBF}$ at $37^{\circ} \mathrm{C}$ for $24 \mathrm{~h}(\mathrm{a}: 0 \%$; b: $5 \%$; c: $10 \%$; d: $15 \%$ )

ever, it increased to 1.45 when the blend ratio of PASP/SF reached $15 \%(\mathrm{w} / \mathrm{w})$. As the proportion of PASP in the blend membranes increased, the content of $\mathrm{Ca}$ in the composite solution also increased clearly. These results in this study proved that apatite had been deposited on the SF substrates successfully. The carbonyl group of PASP enhanced apatite deposition on membranes [18, 26].

\section{Conclusions}

The PASP/SF-HA composites were fabricated through a simple pretreatment and biomimetic method. The addition of PASP and treatment of ethanol greatly influenced the molecular conformation of SF. Intermolecular hydrogen bonds between the carbonyl group of PASP and the polarity group of SF played important roles in the formation of the
PASP/SF-HA composite. The present study may further enhance the understanding of biomineralization and promote the development of new biomaterials for bone tissue engineering.

\section{Acknowledgements}

The authors gratefully acknowledge the support of Natural Science Fund of Anhui Province (Grant Number: 070414193), and the fund support of Key Laboratory of Environment-friendly Polymer Materials of Anhui Province.

\section{References}

[1] Dorozhkin S. V., Epple M.: Biological and medical significance of calcium phosphates. Angewandte Chemie International Edition, 41, 3130-3146 (2002). DOI: 10.1002/1521-3773(20020902)41:17<3130:: AID-ANIE3130>3.0.CO;2-1 
[2] Ducheyne P., Qiu Q.: Bioactive ceramics: The effect of surface reactivity on bone formation and bone cell function. Biomaterials, 20, 2287-2303 (1999). DOI: 10.1016/S0142-9612(99)00181-7

[3] Sikavitsas V. I., Bancroft G. N., Mikos A. G.: Formation of three-dimensional cell/polymer constructs for bone tissue engineering in a spinner flask and a rotating wall vessel bioreactor. Journal of Biomedical Materials Research, 62, 136-148 (2002).

DOI: $10.1002 / \mathrm{jbm} .10150$

[4] Ochi K., Chen G. P., Ushida T., Gojo S., Segawa K., Tai H., Ueno K., Ohkawa H., Mori T., Yamaguchi A., Toyama Y., Hata J-I., Umezawa A.: Use of isolated mature osteoblasts in abundance acts as desiredshaped bone regeneration in combination with a modified poly-DL-lactic-co-glycolic acid (PLGA)-collagen sponge. Journal of Cellular Physiology, 194, 4553 (2003).

DOI: $10.1002 /$ jcp.10185

[5] Yamada Y., Boo J. S., Ozawa R., Nagasaka T., Okazaki Y., Hata K., Ueda M.: Bone regeneration following injection of mesenchymal stem cells and fibrin glue with a biodegradable scaffold. Journal of CranioMaxillofacial Surgery, 31, 27-33 (2003). DOI: $10.1016 / \mathrm{S} 1010-5182(02) 00143-9$

[6] Rocha L. B., Goissis G., Rossi M. A.: Biocompatibility of anionic collagen matrix as scaffold for bone healing. Biomaterials, 23, 449-456 (2002).

DOI: $\underline{10.1016 / \mathrm{S} 0142-9612(01) 00126-0}$

[7] Pulapura S., Kohn J.: Tyrosine-derived polycarbonates: Backbone-modified 'pseudo'-poly(amino acids) designed for biomedical applications. Biopolymers, 32, 411-417 (1992).

DOI: $10.1002 /$ bip.360320418

[8] Pins G. D., Huang E. K., Christiansen D. L., Silver F. H.: Effects of static axial strain on the tensile properties and failure mechanisms of self-assembled collagen fibers. Journal of Applied Polymer Science, 63, 1429-1440 (1997).

DOI: 10.1002/(SICI)1097-4628(19970314)63:11 $\leq 1429::$ AID-APP5>3.0.CO;2-O

[9] Park S. J., Lee K. Y., Ha W. S., Park S. Y.: Structural changes and their effect on mechanical properties of silk fibroin/chitosan blends. Journal of Applied Polymer Science, 74, 2571-2575 (1999).

DOI: 10.1002/(SICI)1097-4628(19991209)74:11 $\leq 2571:$ :AID-APP2>3.0.CO;2-A

[10] Liu L., Liu J. Y., Wang M. Q., Min S. J., Cai Y. R., Zhu L. J., Yao J.M.: Preparation and characterization of nano-hydroxyapatite/silk fibroin porous scaffolds. Journal of Biomaterials Science, Polymer Edition, 19, 325-338 (2008).

DOI: $\underline{10.1163 / 156856208783721010}$

[11] Kong X. D., Cui F. Z., Wang X. M., Zhang W.: Silk fibroin regulated mineralization of hydroxyapatite nanocrystals. Journal of Crystal Growth, 270, 197202 (2004).

DOI: $10.1016 /$ j.jcrysgro.2004.06.007
[12] Wang L., Nemoto R., Senna M.: Changes in microstructure and physico-chemical properties of hydroxyapatite-silk fibroin nanocomposite with varying silk fibroin content. Journal of the European Ceramic Society, 24, 2707-2715 (2004).

DOI: $\underline{10.1016 / j . j e u r c e r a m s o c .2003 .09 .006 ~}$

[13] Nam J., Park Y. H.: Morphology of regenerated silk fibroin: Effects of freezing temperature, alcohol addition, and molecular weight. Journal of Applied Polymer Science, 81, 3008-3021 (2001).

DOI: $10.1002 / a p p .1751$

[14] Chen X., Knight D. P., Shao Z. Z.: $\beta$-turn formation during the conformation transition in silk fibroin. Soft Matter, 5, 2777-2781 (2009).

DOI: $10.1039 / \mathrm{b} 900908 \mathrm{f}$

[15] Chen X., Li W. J., Yu T. Y.: Conformation transition of silk fibroin induced by blending chitosan. Journal of Polymer Science Part B: Polymer Physics, 35, 2293-2296 (1997).

DOI: 10.1002/(SICI)1099-0488(199710)35:14<2293:: AID-POLB9>3.0.CO;2-X

[16] Yang G., Zhang L., Peng T., Zhong W.: Effects of $\mathrm{Ca}^{2+}$ bridge cross-linking on structure and pervaporation of cellulose/alginate blend membranes. Journal of Membrane Science, 175, 53-60 (2000). DOI: $\underline{10.1016 / \mathrm{S} 0376-7388(00) 00407-5}$

[17] Liang C. X., Hirabayashi K.: Improvements of the physical properties of fibroin membranes with sodium alginate. Journal of Applied Polymer Science, 45, 1937-1943 (1992). DOI: 10.1002/app.1992.070451108

[18] Kim H. J., Kim U-J., Kim H. S., Li C. M., Wade M., Leisk G. G., Kaplan D. L.: Bone tissue engineering with premineralized silk scaffolds. Bone, 42, 12261234 (2008).

DOI: $10.1016 / \mathrm{j}$. bone.2008.02.007

[19] Li Y. C., Cai Y. R., Kong X. D., Yao J. M.: Anisotropic growth of hydroxyapatite on the silk fibroin films. Applied Surface Science, 255, 16811685 (2008).

DOI: 10.1016/j.apsusc.2008.06.009

[20] Yang G., Zhang L. N., Liu Y. G.: Structure and microporous formation of cellulose/silk fibroin blend membranes: I. Effect of coagulants. Journal of Membrane Science, 177, 153-161 (2000).

DOI: $10.1016 / \mathrm{S} 0376-7388(00) 00467-1$

[21] Simonetti M., Di Bello C.: New Fourier transform infrared based computational method for peptide secondary structure determination. I. Description of method. Biopolymers, 62, 95-108 (2001). DOI: $10.1002 /$ bip.1002

[22] Cai X., Tong H., Shen X. Y., Chen W. X., Yan J., Hu J. M.: Preparation and characterization of homogeneous chitosan-polylactic acid/hydroxyapatite nanocomposite for bone tissue engineering and evaluation of its mechanical properties. Acta Biomaterialia, 5, 2693-2703 (2009).

DOI: $\underline{10.1016 / j . a c t b i o .2009 .03 .005}$ 
[23] He S-J., Valluzzi R., Gido S. P.: Silk I structure in Bombyx mori silk foams. International Journal of Biological Macromolecules, 24, 187-195 (1999). DOI: $10.1016 / \mathrm{S} 0141-8130(99) 00004-5$

[24] Kratky O., Schauenstein E., Sekora A.: An unstable lattice in silk fibroin. Nature, 165, 319-320 (1950). DOI: $10.1038 / 165319 \mathrm{a} 0$
[25] Tao W., Li M. Z., Zhao C. X.: Structure and properties of regenerated Antheraea pernyi silk fibroin in aqueous solution. International Journal of Biological Macromolecules, 40, 472-478 (2007).

DOI: $10.1016 /$ j.ijbiomac.2006.11.006

[26] Garcia-Fuentes M., Giger E., Meinel L., Merkle H. P.: The effect of hyaluronic acid on silk fibroin conformation. Biomaterials, 29, 633-642 (2008).

DOI: $10.1016 /$ j.biomaterials.2007.10.024 